\title{
A FORMAÇÃO PROFISSIONAL DO ASSISTENTE SOCIAL EM CURSO DE GRADUAÇÃO A DISTÂNCIA: A PERCEPÇÃO DAS TUTORAS
}

\author{
PROFESSIONAL TRAINING OF SOCIAL WORKERS \\ AT UNDERGRADUATE DISTANCE COURSES: THE \\ PERCEPTION OF TUTORS
}

\author{
Daisy Dias Lopes* \\ Eloísa Helena Santos ${ }^{* *}$
}

\begin{abstract}
RESUMO
O presente artigo traduz, parcialmente, a pesquisa que abordou a expansão do ensino a distância no Brasil, em especial em curso de graduação em Serviço Social, e suas implicações na qualidade da formação do futuro assistente social. O objetivo foi analisar a formação de estudantes do curso de graduação em Serviço Social, na modalidade a distância, ofertada em polos presenciais de uma instituição de ensino superior, em Minas Gerais, por intermédio da atuação dos tutores presenciais. Optou-se por uma metodologia qualitativa, que melhor se adéqua ao problema sob análise, com a realização de entrevistas e questionários. Os principais resultados obtidos revelam implicações diretas na formação desses futuros profissionais e apontam fragilidades no uso das tecnologias de informação e comunicação no âmbito educacional, aligeiramento no processo de ensino e aprendizagem no que diz respeito à apreensão de conhecimentos estruturadores da profissão do assistente social; dificuldades e precariedade na realização do estágio supervisionado; poucas oportunidades de discussão ética e política das questões que envolvem o Serviço Social.
\end{abstract}

Palavras-chave: Educação a distância. Formação profissional. Tutoria presencial.

\begin{abstract}
The present article discusses research that investigated the expansion of distance education in Brazil, in particular Social Work undergraduate courses, and its implications in the quality of the education of future social workers. The aim was to analyze the education of students of Social Work undergraduate courses in distance delivery offered in face-to-face centers at an institution of higher education in Minas Gerais, through the mediation of face-to-face tutors. The study was carried out using a qualitative methodology as it is suitable for the problem under analysis; the study included interviews and questionnaires. The main results demonstrate direct implications for the formation of these future professionals and point out weaknesses in the use of information communication technologies concerning educational aspects; the results also demonstrate a shorter teaching and learning process in relation to the apprehension of fundamental knowledge
\end{abstract}

\footnotetext{
"Mestre em Gestão Social, Educação e Desenvolvimento Local. Centro Universitário UMA. E-mail: <daisygripp@yahoo.com.br>.

** Doutora em Educação, pós-doutora em Sociologia do Trabalho e em Ergologia. Centro Universitário UMA. E-mail: <eloisasantos@uaivip.com.br>.
} 
for social workers; difficulties and precariousness in the accomplishment of the supervised internship as well as few opportunities of ethical and political discussions of the questions that involve Social Service.

Keywords: Distance learning education. Professional Training. Face-to-face Tutoring.

\section{Introdução}

A sociedade dos nossos dias vivenciou e continua vivenciando mudanças nas dimensões sociais, econômicas, políticas e culturais de forma acelerada e nunca antes imaginada. Tais mudanças são demandadas para acompanhar o grande caldeirão de transformações operadas na vida dos cidadãos, das empresas, dos governos, pelas tecnologias que são colocadas disponíveis numa incansável escalada de inovações. A popularização das tecnologias informacionais e computacionais, bem como o estágio em que se encontra a sociedade pós-industrial, tem operado uma verdadeira revolução no cotidiano dos cidadãos.

Conforme alerta Morin et al. (2007), a mundialização da economia por meio do impulso e aceleração proporcionada pelas TICs - Tecnologias de Informação e Comunicação - alimenta o quadrimotor ciência, técnica, indústria e interesse econômico. Fortalece, também, a ideologia do progresso e esta dinâmica unifica, divide, iguala, provoca desigualdades e degradação da qualidade de vida. Produzem uma ambivalência e se transformam num mal-estar global para uma civilização submetida à atomização, ao anonimato, à perda de sentido.

Tais mudanças operadas no seio da sociedade se refletem, também, no meio educacional. As tecnologias de informação e comunicação vieram ampliar o universo destas mudanças permitindo, quando adotadas, novas formas de realização do processo de ensino e aprendizagem. Uma das inovações marcantes nos processos educacionais é o ensino a distância, incrementado, principalmente, a partir da internet e outras mídias, que vieram se conectar aos desafios postos à educação brasileira quanto à universalização do acesso aos vários níveis de ensino.

A política educacional brasileira reconheceu o ensino a distância como uma das possibilidades de ampliação do acesso à educação por meio do artigo
80 da Lei de Diretrizes e Bases da Educação Nacional - LDBEN - Lei no 9.394 de 1996, que preconiza: "O Poder Público incentivará o desenvolvimento e a veiculação de programas de ensino a distância, em todos os níveis e modalidades de ensino, e de educação continuada."

Para o Ministério de Educação e Cultura (MEC), o decreto $\mathrm{n}^{\circ} 5.622$ (2005) caracteriza a educação a distância, sob a perspectiva das tecnologias de informação e comunicação, como

[...] a modalidade educacional, na qual a mediação didático-pedagógica nos processos de ensino e aprendizagem ocorre com a utilização de meios e tecnologias de informação e comunicação, com estudantes e professores desenvolvendo atividades educativas em lugares ou tempos diversos.

Assim, a partir de 2005, com a regulamentação legal, a educação a distância ganha impulso principalmente no ensino superior. Embora muita ênfase seja dada à metodologia e ao papel das TIC's pelas suas possibilidades de aplicação no contexto educacional, é importante que se compreenda a educação a distância como um fenômeno complexo, que envolve os sujeitos do processo educacional inseridos na sociedade da informação, e como uma modalidade que interfere na formação e qualificação profissional.

A implantação dessa modalidade de ensino, como tudo o que é desconhecido, é marcada, neste primeiro momento, por uma posição de baixo prestígio, de solução paliativa, emergencial, em relação ao ensino presencial. A sociedade em geral e, até mesmo, profissionais do campo da educação veem o ensino a distância como ação supletiva, destinada a um público que teve dificuldades de acesso à educação tradicional, que utiliza modelos simplificadores, com foco em avaliações somativas, estandartizadas e quantitativas. Seus cursos focalizam mais a transmissão de conteúdo do que a pesquisa, a leitura pronta do que a realização de projetos, além de não traduzirem confiança quanto à qualidade do 
ensino e da aprendizagem (MORAN, 2005). Portanto, conforme Belloni (2006), essa visão diluída no senso comum sugere dúvidas quanto à qualidade dessa modalidade de ensino, apesar de relatos de experiências exitosas em universidades europeias e americanas.

Uma significativa expansão desses cursos, principalmente a partir de 2006, e denúncias sobre a sua precariedade causaram impactos negativos no interior da categoria profissional dos assistentes sociais e órgãos representativos do Serviço Social, que passaram a se mobilizar em torno do fenômeno. Com a qualidade da formação, já diagnosticada deficitária em boa parte de cursos presenciais, que também sofreram uma vertiginosa expansão a partir de 2000, a perspectiva da modalidade a distância, ainda desconhecida de muitos, provocou resistências, dúvidas e receios quanto à sua efetividade na formação dos profissionais.

Alguns assistentes sociais de Minas Gerais levaram ao Conselho Regional de Serviço Social - CRESS $6^{a}$ Região - manifestações quanto à explosão dos cursos de graduação em Serviço Social, presenciais e a distância, e chamaram a atenção para a qualidade da formação ofertada e seus reflexos no exercício profissional. Esses dados foram levantados no período de janeiro a março de 2008 junto ao setor de orientação e fiscalização do Conselho e expressaram a preocupação com os rumos da profissão, o atendimento aos usuários dos serviços dos assistentes sociais, a precarização da formação e o poder de fiscalização do Conselho, e previram ameaças decorrentes de uma formação de má qualidade ao espaço já conquistado profissionalmente.

Quanto à formação profissional, os assistentes sociais abordaram inquietações relativas ao processo de mercantilização da educação, questionaram o modelo do novo "curso a distância" quanto à carga horária, metodologias, conteúdos, valor das mensalidades, capacidade deste tipo de curso em oferecer bagagem teórica, metodológica, ética e política que mantenha a sustentação do projeto ético-político profissional da categoria, além da capacidade de oferecer uma formação de qualidade.

Além dessas inquietações, os profissionais tomaram conhecimento de realização inadequada de supervisão direta de estágios com inexistência de convênios formais entre instituição de ensino e instituições de campo de estágio. Registraram que alguns profissionais que se negaram a supervisionar alunos provenientes dessa modalidade de ensino sofreram pressões seguidas de ameaças pelas chefias de algumas instituições públicas.

Quanto ao exercício profissional, levantaram observações relativas à desvalorização e sucateamento da profissão com consequente banalização do curso de Serviço Social e provável achatamento das ofertas salariais. Creditam à fragilidade da formação o formato aligeirado do curso, supondo a reedição de um perfil profissional, refém de práticas conservadoras junto da política partidarista, do clientelismo e do assistencialismo, principalmente, no espaço dos pequenos e médios municípios. Alertaram para o tipo de serviço questionável que deverá ser prestado aos usuários do Serviço Social.

Quanto à atuação dos órgãos representativos da categoria, questionam a capacidade e alcance da fiscalização aos profissionais e campos de estágios envolvidos nessa modalidade de ensino; sobre a legalidade dos cursos e concessão de registro profissional.

Alguns estudantes do curso de Serviço Social, de escolas de ensino presencial e a distância, também se dirigiram ao CRESS buscando informações sobre a legalidade dos cursos, a obtenção de registro profissional e a negativa dos assistentes sociais de campo em supervisionar alunos de ensino a distância (EAD), sobre material para estudo e orientações diversas. A maioria dos questionamentos e preocupações dos alunos dessa nova modalidade foi a respeito do reconhecimento dos cursos pelo Conselho, e da emissão e fornecimento do registro profissional. Preocupam-se se haverá registro com distinção quanto à modalidade do curso.

Quanto à supervisão direta de estágios, os estudantes relataram negativas dos assistentes sociais de campo em supervisioná-los, sob alegação de que o Conselho não autoriza a realização de tal atribuição privativa aos alunos de EAD. Apresentaram preocupação em relação ao futuro profissional, tendo em vista que ouviram dizer que "quem faz este curso, em alguns lugares, não aceitam nem fazendo concurso".

Saliente-se que, dentre um total de 17 correspondências eletrônicas recebidas dos estudantes, apenas três registram preocupação com a formação 
no sentido estrito e solicitaram orientação ao CRESS no envio de material para complementar seus estudos.

Como se pode observar, as preocupações dos assistentes sociais e estudantes dizem respeito não somente ao processo de mercantilização e precarização do ensino superior a distância, como também se referem aos riscos que afetam os cursos de Serviço Social e quanto à materialização do projeto ético político profissional, que orienta a atuação dos assistentes sociais.

Nesse conjunto de elementos apresentados anteriormente, identifica-se o problema em foco nesta pesquisa. Trata-se da formação dos futuros assistentes sociais, na modalidade a distância, tendo em vista a tarefa de construção do perfil profissional preconizado pelas diretrizes curriculares e balizado pelo código ético-político da profissão.

Assim, diante das fragilidades diagnosticadas pelos órgãos representativos da categoria profissional e polêmicas em discussão, realizou-se esta pesquisa com o objetivo de analisar a formação dos futuros assistentes sociais na modalidade a distância ofertada em polos de ensino a distância de uma instituição de ensino superior, em Minas Gerais, por meio do trabalho da tutoria presencial.

A partir da opção por uma metodologia qualitativa, a pesquisa desenvolveu-se em três momentos. Num primeiro momento, uma revisão bibliográfica possibilitou estabelecer um diálogo com autores que discutem o tema em foco. Em seguida, uma pesquisa de campo permitiu a aproximação com o fenômeno que se desejava analisar por meio de entrevistas e questionários. Finalmente, os dados coletados na pesquisa empírica foram cotejados com a discussão teórica e analisados.

Portanto, com vistas à consecução dos objetivos desta pesquisa e operacionalização da metodologia adotada - estudo de caso -, foram estabelecidas cinco fases que constaram da coleta de dados.

$\mathrm{Na}$ primeira fase da pesquisa, foi acessada a documentação disponibilizada pela IES, por intermédio da sua página eletrônica, para obter dados para a realização do mapeamento dos polos presenciais em Minas Gerais relativos aos cursos de Serviço Social, o seu projeto pedagógico e demais documentos, que se mostraram de interesse aos objetivos desta investigação.
Na segunda fase da pesquisa, foram aplicados questionários aos tutores presenciais do curso de Serviço Social, nos nove polos de apoio presencial selecionados. Considerando a familiaridade dos tutores presenciais com o ambiente virtual, o questionário, depois de pré-testado, foi desenvolvido e programado em formato php4, visando dar celeridade e funcionalidade aos respondentes.

$\mathrm{Na}$ terceira fase da pesquisa, foram feitos contatos com 11 tutores para a realização das entrevistas, dos quais se obteve quatro tutores presenciais disponíveis e interessados em participar da entrevista.

$\mathrm{Na}$ quarta fase, os dados de campo recolhidos foram ordenados, classificados, processados e sistematizados para responder aos objetivos da pesquisa. Os dados organizados foram analisados e interpretados sob o ponto de vista do referencial teórico e os resultados examinados à luz dos objetivos propostos, procurando-se identificar os padrões relevantes.

Para se chegar à análise dos resultados da pesquisa foi, primeiramente, feita uma leitura exploratória das transcrições das entrevistas gravadas com a organização dos dados e após esta organização nova leitura foi realizada, com identificação da constância de certas palavras, frases e formas de os participantes compreenderem o fenômeno sob análise.

$\mathrm{Na}$ quinta fase, construiu-se o texto da dissertação, que originou uma proposta de intervenção direcionada a subsidiar as ações do CRESS $6^{\text {a }}$ Região na sua atividade precípua - a fiscalização do exercício profissional dos assistentes sociais em Minas Gerais.

Sinteticamente, os dados mostraram a expansão e investimentos no ensino a distância, mas apontaram para a necessidade premente da ampliação das discussões sobre a qualidade desta modalidade no processo educacional, bem como suas repercussões no exercício profissional e no mercado de trabalho. Afinal, trata-se de uma metodologia educacional recente, que, assim como as demais, apresenta potencialidades e limitações.

\section{Formação profissional e política educacional}

Pensar a formação profissional de estudantes brasileiros não está dissociado do contexto da educação, seus nexos históricos, sua inserção no 
processo de globalização e da mundialização do capital.

Historicamente, a política educacional brasileira se desenvolveu privilegiando as elites dominantes e exercendo um papel de exclusão dos segmentos menos favorecidos quanto ao acesso à educação.

Em resumo, da década de 1930 a 1970, observou-se um Estado nacional forte voltado para um sistema econômico de amplitude nacional. O projeto nacionalista foi abortado a partir do golpe militar engendrado pela elite com conotação muito mais de um golpe de classe do que essencialmente militar. Abriu-se, então, o país para a lógica do capitalismo transnacional de viés, altamente excludente. Nos anos 1970, com a inovação tecnológica, tanto da informação quanto da comunicação, toma corpo não só no Brasil, mas em toda a América Latina, o Estado liberal, que propôs a diminuição do Estado e em cuja doutrina o bem-estar social estava vinculado ao estabelecimento de relações capitalistas de mercado, livre negociação de salários e de relações de consumo.

As principais características dessa fase do capitalismo estão vinculadas e centralizadas na globalização da economia, com redução acentuada das fronteiras econômicas, o desmonte do Estado e a destruição dos direitos sociais como educação, saúde, habitação, transporte, trabalho etc. Essa concepção de Estado, com a globalização e seus efeitos, vem, politicamente, refletir no autodesenvolvimento dos povos que, segundo Arruda (1995, p. 6), passou a afetar

[...] comunidades e nações de ambos os hemisférios. Um clima de incerteza e instabilidade se avoluma no próprio mundo rico. Os avanços tecnológicos e organizativos da produção, a maré sempre mais abundante de produtos de consumo, e sobretudo a hipertrofia da atividade financeira especulativa resultante da desregulação e do progresso telemático, têm sido acompanhados de crise financeira e fiscal dos estados, do crescimento econômico sem aumento de oferta de emprego e de deterioração ambiental. Isto lança no desespero um número crescente de famílias trabalhadoras e nutre um crescente abismo social nos países ricos. Enfraquece as organizações dos trabalhadores e alimenta sentimentos xenófobos e racistas contra os imigrantes vindos de países pobres.
Tais repercussões se fazem sentir no nosso país impactando as mais diversas áreas da vida social e, indubitavelmente, atingem nossa política educacional. Portanto, o impacto da reforma do Estado na política educacional brasileira, a partir dos anos 1990, está presente na busca de racionalização de recursos reduzindo-se seu papel no tocante às políticas sociais. A estratégia utilizada pelo governo federal, neste momento, para fazer frente à crise do capital instalada globalmente, baseou-se na atração especulativa, via política de juros altos, que produziu o aumento das dívidas interna e externa e provocou a crise fiscal em estados e municípios. Agregue-se a este quadro que a municipalização das políticas sociais se dá no momento em que os entes federados estão preocupados em saldar dívidas com a União, consequentemente, sem recursos para investir em políticas sociais. O que se assistiu foi a configuração de um Estado mínimo para as políticas sociais e um Estado máximo para o capital.

No ensino superior, a reforma universitária, de acordo com a análise do ANDES - Sindicato Nacional dos Docentes das Instituições de Ensino Superior (TRÓPIA, 2008) -, sob a alegação de revitalização das universidades públicas, regulamentação do setor privado e democratização do acesso, veio para contribuir com a privatização do sistema federal de ensino superior.

O que parece estar em curso é a transformação da autonomia das universidades públicas à captação de recursos financeiros, uma total autonomia às IES privadas, o tratamento do repasse de recursos financeiros com condicionalidades (de desempenho, corte de recursos, captação de recursos na iniciativa privada por meio das fundações) e por fim a abertura para o capital internacional do ensino superior.

Segundo, ainda, o ANDES, tal remodelação no sistema educacional brasileiro visa, entre tantos objetivos, consolidar a abertura do mercado educacional brasileiro ao capital internacional, e dentre as alternativas a educação a distância seria um dos mercados de forte interesse.

Tal concepção política de um Estado neoliberal atravessa a grande maioria das políticas sociais e seu reflexo na educação é percebido, entre outros, pela ênfase na privatização da política educacional em detrimento de uma educação pública, gratuita e democrática. 


\section{Tutoria presencial na instituição investigada}

Para a pesquisa foi selecionada uma instituição de ensino superior que se denominou UNISOCIAL. A instituição vem se expandindo no seu estado de origem e atua no cenário da educação há mais de três décadas. Sua trajetória vem da transformação de um colégio de ensino médio em unidades de ensino superior, por iniciativa de um grupo de empresários. Trata-se, portanto, de uma sociedade empresarial de natureza jurídica do direito privado com fins lucrativos. No processo de ampliação da UNISOCIAL, a partir de 2002, a instituição foi autorizada pelo MEC para oferecer cursos na modalidade a distância.

A natureza privada da UNISOCIAL está associada ao processo de ampliação mercadológica da empresa educacional na oferta de vários cursos. Esta é uma das características intrínsecas aos padrões da empresa capitalista: buscar a lucratividade. Portanto, a UNISOCIAL, ao atuar dentro da lógica privada, trabalha sob os princípios da acumulação capitalista, embora não se desconsidere a sua contribuição na formação e educação de parcela da sociedade brasileira.

Os cursos a distância ofertados pela UNISOCIAL estão presentes em mais de 400 municípios e 26 estados brasileiros, seja em cursos de graduação, pós-graduação ou de educação corporativa. Dentre os cursos ofertados na modalidade a distância, o curso de Serviço Social, foco da investigação, é oferecido em 26 estados da federação, atingindo 362 polos de apoio presencial. Em Minas Gerais, o curso era oferecido em 55 polos de apoio presencial à época da pesquisa.

Para viabilizar essa modalidade de ensino, foi resgatada de momentos históricos diversos a figura do tutor. $\mathrm{O}$ ensino a distância apresenta aspectos relevantes no exercício da tutoria já indicados em alguns estudos (BELLONI, 2006; LITWIN, 2001; MAGGIO, 2001). À tutoria no ensino a distância, de modo geral, compete orientar, acompanhar o processo de aprendizagem, relacionar-se com os estudantes, avaliar atividades, entre outras. Todavia, algumas instituições que supervalorizam os materiais didáticos e as ações dos estudantes tendem a atribuir, a esta função, um valor secundário. Na pesquisa realizada com tutoras presenciais de curso de
Serviço Social na modalidade a distância ficou registrada a visão que estas profissionais têm de suas próprias atribuições:

[...] eu vejo o papel do tutor muito ligado a motivar este aluno nesta busca por este conhecimento, que é um modelo de ensino, que se o aluno não tiver vontade de buscar para além daquilo que é oferecido, é pouco [...] o tutor enquanto articulador deste processo ele tem um papel importante. (Tutora presencial 3).

Para exercer este papel de motivação, articulação ou mediação, a instituição investigada vem utilizando assistentes sociais, cujo perfil evidenciado, segundo resultados obtidos na pesquisa, aponta para profissionais que possuem formação em Serviço Social - portanto, todas são assistentes sociais. Quanto ao gênero, são $100 \%$ do sexo feminino, confirmando Iamamoto (2001, p. 104):

[...] no Serviço Social tem-se um contingente profissional hoje proveniente de segmentos médios pauperizados, com um nítido recorte de gênero: uma categoria profissional predominantemente feminina, uma profissão tradicionalmente de mulheres para mulheres.

Ainda quanto ao gênero, a pesquisa sobre o perfil do assistente social brasileiro: Assistentes Sociais no Brasil - elementos para o estudo do perfil profissional - divulgada pelo Conselho Federal de Serviço Social - CFESS e realizada pela Universidade Federal de Alagoas (2005) já apontava para uma categoria constituída por $97 \%$ de mulheres e apenas 3\% representando os homens.

Quanto à faixa etária, 55\% das profissionais se situam entre 25 a 30 anos; $27 \%$ estão com menos de 25 anos; $9 \%$ têm de 31 a 40 anos; e outros $9 \%$ estão com mais de 50 anos, conforme os dados coletados.

O grupo pesquisado possui experiência profissional recente na educação. A maioria das tutoras, à época da pesquisa, possuía menos de um ano na docência em EAD e não vinha de experiências anteriores na educação presencial. Como assistentes sociais, trabalhavam na esfera pública municipal, com maior concentração na área da política da assistência social e da saúde. Houve relatos, ainda, de vínculos de trabalho no poder judiciário estadual e em organizações não governamentais. 
Além da formação em Serviço Social, as tutoras apresentaram especialização lato sensu diversificada, tais como Gestão de Políticas Sociais; Atendimento Integral à Família; Serviço Social: Direitos Sociais e Competências Profissionais (cursando); Educação Inclusiva; Política e Pesquisa em Saúde Coletiva; Violência contra Crianças e Adolescentes; Análise Institucional; Gestão do Sistema Único de Assistência Social (SUAS); e Política Nacional de Assistência Social (PNAS).

Tais dados denotam um perfil profissional de jovens tutoras. Ao se cruzar os dados da faixa etária com a formação profissional, tem-se assistentes sociais que se tornaram tutoras recém-saídas da graduação. A maioria das entrevistadas graduou-se no período referente a 2004/2007. São, também, em sua maioria, profissionais inseridas há pouco tempo no mercado de trabalho.

Para as profissionais é atribuída significativa importância ao seu papel como motivadoras dos estudantes na construção da formação, uma vez que se trata muito mais de uma função incentivadora, que promova no aluno o desejo de continuar com o curso, que o motive para o processo educacional.

\section{O perfil dos estudantes em curso de graduação mediado por tecnologia de informação e comunicação}

Para atuar, profissionalmente, na complexa sociedade contemporânea dos nossos dias, a formação deverá corroborar com a construção de um perfil profissional o mais globalizante possível. $\mathrm{Na}$ visão de Litwin (2001), uma universidade deveria formar para além da competência para o trabalho ou produção de conhecimentos, mas ser capaz de proporcionar uma formação que alcance um desenvolvimento integral, seja na esfera pessoal, individual e coletiva, seja na participação política.

É função da universidade buscar a formação e o desenvolvimento de um sujeito integral, cidadão participativo, do seu tempo. Igualmente, a sociedade contemporânea, em especial o mercado capitalista, exige do aluno de ensino superior uma formação capaz de lidar com situações complexas, novas tecnologias, relações de trabalho quase sempre precarizadas e exigências de multicompetências, multiqualificações com capacidades de gestão e trabalho em equipe, adaptações a novas situações, educação continuada - em suma, um trabalhador bem-informado e autônomo (BELLONI, 2006). Para este perfil de trabalhador, Belloni (2006) afirma que o ensino a distância, mais do que o ensino presencial, terá condições de contribuir com a formação de um estudante mais autônomo, uma vez que a autoaprendizagem deve ser a característica deste público.

No entanto, a autora registra que não tem sido esta a imagem captada do estudante de ensino a distância - um aprendente autônomo. Pelo contrário: estudos mostram que muitos alunos dessa modalidade de ensino demonstram tendência a exercitar "uma aprendizagem passiva digerindo pacotes instrucionais e regurgitando conhecimentos assimilados nas avaliações" (BELLONI, 2006, p. 40). Relata que tal fenômeno pode ser explicado pelo tipo de concepção do curso, práticas industrializadas, materiais inadequados, mas que encerram uma outra dimensão, que são as características e condições de estudo dos "aprendentes".

Na pesquisa realizada, as tutoras presenciais registraram que o público do curso de Serviço Social, de suas respectivas unidades, em sua maioria, é composto de pessoas maduras que, por questões variadas, tais como necessidade imperiosa de ir para o mercado de trabalho mais cedo, distância dos centros de educação superior, entre outros, ficaram impossibilitadas de prosseguir com os estudos.

A tutora entrevistada registra a diversidade do público que procura o curso de Serviço Social nessa modalidade:

[...] Você tem alunos que saíram do ensino médio, você tem público do Projovem, você tem pessoas que têm 30 anos que não vão à escola. Você tem pessoas que já estavam ligadas à área, como por exemplo secretários de assistência social, você tem coordenador de CRAS [Centro de Referência da Assistência Social], que era formado em Pedagogia e está fazendo Serviço Social, você tem um público-alvo muito diversificado, eu tenho uma mãe e uma filha na mesma sala. (Tutora presencial 4).

Embora encontrem estudantes egressos do ensino médio, outra tutora registra que a maioria do público do ensino a distância, no curso de Serviço Social investigado, é composta por pessoas mais experientes e relata 
[...] ter encontrado alunos que conseguiram sair do ensino médio há pouco tempo e vieram para a graduação do ensino a distância. Mas na minha percepção, o público maior é de pessoas que já pararam de estudar há muito tempo e que trabalham, trabalham até hoje com uma carga de trabalho extensa e aí veem no ensino a distância um facilitador por isso, porque é uma vez na semana que eles têm de estar presentes, então é o público que já parou de estudar, já concluiu o ensino médio há muito tempo e que sempre teve vontade de ser graduado, de ter uma graduação, encontrou no ensino a distância esta facilidade. (Tutora presencial 1).

Essas características do público que demanda o ensino a distância, se por um lado aponta para a maturidade na opção por essa modalidade, por outro demonstra um público pressionado pelo reduzido número de horas disponíveis para a dedicação aos estudos. A equalização dessa necessidade ou desejo de se qualificar, terminar os estudos, se formar, com a disponibilidade do tempo para os estudos aparece como condição inerente a uma formação de qualidade. Essas características pressupõem necessidades diferenciadas em termos de metodologias de ensino e aprendizagem e avaliativas. Cabe, aqui, interrogar se os cursos oferecidos nessa modalidade levam em consideração esse perfil do alunado?

As tutoras atribuem, também, ao valor das mensalidades e à obrigatoriedade de se estar presente apenas uma vez por semana, no polo presencial, atrativos para a escolha do ensino a distância pela maioria dos estudantes. O depoimento da tutora expressa essas condições:

[...] o custo do ensino a distância hoje é bem menor do que o ensino presencial. A segunda coisa é a facilidade em relação a tempo; por exemplo, o ensino presencial, você tem que estar disponível toda noite, no ensino a distância você se adapta aos trabalhos que você faz pelo computador e somente um dia por semana você vai prá lá. Eu acho que isto é fator indispensável, é o tempo e o custo. (Tutora presencial 4).

As tutoras reforçam ainda o fato de que os fatores, custo e tempo, são o grande atrativo na escolha da modalidade:

[...] o aluno não tem dinheiro para acessar a graduação presencial, então tem aí uma questão de acesso mesmo, por questões objetivas. Então, por isso, ele vai para o ensino a distância. E eu acho que também por um atrativo de que o compromisso é um dia na semana, uma noite. Isto facilita, claro, se você tem filho, se você tem família, se você trabalha o dia inteiro, se você tem opção de fazer uma graduação onde você vai ter que ir só uma noite, você vai porque, se você for para todas as noites, você não vê o seu filho mais, até você terminar a graduação. Então eu acho que estas duas coisas são motivadoras para a escolha deste tipo de ensino. (Tutora presencial 3).

Outro fator importante a ser considerado no perfil dos estudantes do curso de Serviço Social a distância investigado é o domínio das tecnologias de informação e comunicação indispensável ao modelo virtual.

As tutoras entrevistadas revelaram que, em relação ao acesso e domínio das TIC's pelos estudantes, há situações em que

[...] mesmo que o aluno chegue no primeiro período e não saiba mexer [no computador], porque tem gente que vai pro ensino a distância que não sabe ligar um computador, não sabe acessar, mas eles sempre conseguem alguém ali pra ajudar. Um filho, um sobrinho, um parente. E eu percebo que a partir do segundo semestre eles já estão bem inteirados, ainda que ele não tenha o computador em casa ele consegue ali na sua rede relacional conseguir algum para atender sua demanda. (Tutora presencial 3).

Os polos em que estão as tutoras entrevistadas, para minimizar tais aspectos, adotam plantão para orientar ou ensinar os alunos que ainda não dominam as TIC's. Além de reforço para que o estudante se familiarize com a tecnologia, outras possibilidades são colocadas:

[...] o polo tem laboratório, são computadores ligados à internet que podem ser disponibilizados pela manhã, pela tarde e à noite. Cada semestre a aula é em um dia da semana, no restante da semana o aluno que tiver interesse, que quiser vir estudar, o polo tem uma biblioteca formada, tem laboratório. Esse aluno, qualquer horário do dia ou da noite, tem acesso livre porque ainda temos alunos que escolhem curso a distância sem ter computador em casa. (Tutora presencial 2).

Cabe questionar se alunos que optaram por um curso que não demanda presença física em sala 
de aula, por absoluta falta de tempo e outros compromissos, terão como utilizar este tempo disponibilizado para o plantão.

Uma das marcas do ensino a distância é a autonomia que deve caracterizar seus estudantes ou ser desenvolvidas nestes, para que obtenham sucesso na aprendizagem. As tecnologias da informação e comunicação que abrem as portas ao ciberespaço e a possibilidade de se estudar, onde e quando for conveniente ao aluno, exigem em contrapartida uma maturidade e capacidade de gerenciamento das práticas de aprendizagem e estudo, moldando ou resultando daí um sujeito e aprendiz autônomo.

Belloni (2006) considera a autoaprendizagem um fator básico para a realização do ensino a distância e que esta contribui para formar um estudante autônomo. $\mathrm{O}$ aluno autônomo no ensino a distância é aquele capaz de se autodirigir, se autorregular, ou seja, de gerir seu próprio processo de aprendizagem. A autora afirma, ainda, que o desenvolvimento dessa modalidade de ensino pressupõe alunos adultos com maturidade e motivação suficientes para que se dê a autoaprendizagem. Num processo educativo autônomo o estudante deixa de ser objeto ou produto, mas passa a configurar um sujeito ativo, responsável pela sua própria aprendizagem, significando que após compreender é capaz de abstrair os conhecimentos e aplicá-los a situações novas.

As tutoras entrevistadas referiram como próprio do perfil de seus alunos a busca por complementação do conhecimento oferecido nas teleaulas e outras experiências educativas: "[...] o aluno tem uma liberdade, inclusive, até um incentivo ao autoestudo, que eu acho que isto instiga no aluno a ter uma disciplina, uma responsabilidade frente aos seus estudos, que eu acho chega a ser até maior do que no ensino presencial." (Tutora presencial 1).

Embora, como alegado por vários autores, a autonomia seja uma característica indispensável ao aluno do ensino a distância, segundo afirma Belloni (2006, p. 41), a mesma é incomum no universo dos estudantes brasileiros, que desde os anos iniciais de escolarização não são preparados para esta autonomia e independência, pois "o conceito de aprendente autônomo, ou independente, capaz de autogestão de seus estudos é ainda embrionário, do mesmo modo que o estudante autônomo é ainda exceção no universo de nossas universidades, abertas ou conven- cionais".

Para os autores que discutem a educação a distância, esse perfil do aluno brasileiro está ligado à "educação bancária” que Freire (2002, p. 68) criticou quando afirmou que "ninguém educa ninguém, ninguém educa a si mesmo, os homens se educam entre si, mediatizados pelo mundo".

Aqui, não se deve confundir tal processo de autonomia com o autodidatismo, destituído de orientação pedagógica ou de diálogos com os demais sujeitos envolvidos neste processo. Como esclarece Litwin (2001, p. 14),

[...] a autonomia não deve ser confundida com o autodidatismo, pois um autodidata é o estudante que seleciona conteúdos e não conta com uma proposta pedagógica e didática para o estudo [...] Embora a modalidade a distância permita uma organização autônoma dos estudantes, não se deve esquecer que nela selecionam-se os conteúdos, orienta-se o prosseguimento dos estudos e propõem-se atividades para que os estudantes resolvam os mais complexos ou os mais interessantes problemas. Os programas de educação a distância contêm uma clara proposta didática, talvez, e em contradição com as crenças mais comuns, com maior conteúdo didático que as situações presenciais.

Esse aluno autônomo ou sujeito aprendente demanda um perfil específico de estudante, o qual, segundo as tutoras, vem jogar por terra o mito de que o ensino a distância é fácil. Para que o aluno leve a bom termo seus estudos,

[...] não é só o aluno ir à escola, assistir à teleaula, fazer a aula-atividade, acabou, não. $\mathrm{O}$ ensino a distância ainda tem os exercícios que os alunos fazem, duas aulas que são na web. Para cada duas aulas você tem uma prova, cada disciplina você tem quatro aulas na WEB e duas provas na WEB e um trabalho de portifólio em que o professor escolhe determinado tema e os alunos vão a campo pesquisar, em livros, na própria internet, e em outros campos sobre, fazem entrevistas sobre o tema que o professor escolheu. (Tutora presencial 4).

No contexto da formação profissional, um curso mediado pela tecnologia da informação e comunicação lida com o desafio de transformar as diretrizes curriculares em conhecimento e habilidades indispensáveis ao exercício profissional. 
No caso específico do curso de Serviço Social, a partir do projeto pedagógico da instituição, que propõe formar o estudante de maneira generalista e crítica, a fim de intervir nas diferentes expressões da questão social, fundamentado na concepção crítica da realidade, as tutoras concordam que o currículo atende às orientações das diretrizes nacionais curriculares para os cursos de Serviço Social, pois

[...] os professores e também o material que eles utilizam são muito dentro do que é proposto pelas diretrizes. Ele fornece uma visão crítica para os alunos dessa posição muito contraditória do surgimento do Serviço Social, aliado mais à burguesia. Eles têm fundamentos marxistas também, desde o início da disciplina de fundamentos históricos, teóricos e metodológicos. A formação social, política e econômica do Brasil também procura mostrar toda a contradição, as consequências da nossa formação, da escravidão e a repercussão no modo de vida nosso hoje, então acho que está muito dentro, o curso tenta passar para o aluno uma visão bem crítica e real. (Tutora presencial 1).

No entanto, mesmo acreditando que o curso atenda às diretrizes curriculares, as tutoras apontam uma questão pertinente ao processo do ensino a distância. Destacam a rapidez com que são ministrados os conteúdos, mas entendem que

[...] teoricamente, atende sim. Teoricamente, se você for pegar o objetivo, a ementa de cada disciplina, atende a todas estas questões dos núcleos das diretrizes nacionais curriculares. Todos os semestres ou períodos têm a disciplina de seminários temáticos, também, que eles buscam temas muito interessantes, mas às vezes eu percebo que duas aulas, por exemplo, para uma disciplina ou alguma disciplina específica, várias delas têm duas ou três aulas, é pouco para o repasse do conteúdo pelo professor, sabe? Mas, assim, o objetivo da disciplina, a ementa, ela contempla tudo. (Tutora presencial 1).

As tutoras entrevistadas confirmam a oferta das disciplinas pelo curso a distância e entendem que, em tese, oferecem uma discussão condizente com o proposto pelas Diretrizes Nacionais Curriculares para os cursos de Serviço Social.

No entanto, registram a carga horária reduzida, tanto para as aulas quanto para o espaço de discussão e debate. Aliado ao tempo reduzido, fica patente a preocupação da tutora com a limitação que é colocada para o "repasse de conteúdo pelo professor", demonstrando, assim, a incorporação do modelo tradicional da educação, que acaba por trazer para o espaço da educação a distância o velho conceito do professor que transmite conhecimentos e a posição passiva do aluno que recebe a informação, totalmente incoerente com o perfil do aluno que nesta modalidade, incontestavelmente, dever ser o centro do processo educativo.

$\mathrm{Ou}$, ainda, comprova a grande chance de que o modelo presencial esteja sendo meramente transportado para o ensino a distância, ao qual se acoplaram as tecnologias da informação e comunicação.

Segundo o que relata uma das tutoras entrevistadas, a organização curricular no ensino a distância propicia esta dinâmica de modo insuficiente, considerando-se o tempo reduzido e a responsabilidade do aluno em realizar a gestão do seu próprio conhecimento,

[...] porque também não dá tempo de ser preparado, de ter um projeto que viabilize que o aluno tenha mais do que na teleaula, se ele mesmo não procura. Por isso a gente frisa bastante que o aluno do ensino a distância, ele tem que ser autodidata. Porque a teleaula, aula-atividade ou o restante que pode possibilitar um ganho de aprendizado que aumenta o conhecimento é o aluno que tem que se dispor. E é ele que tem que buscar este conhecimento porque o tempo é pouco, uma aula por semana não possibilita este sistema de seminários. (Tutora presencial 2).

Cabe ressaltar que os dados encontrados em campo sinalizam achados e aspectos da formação dos estudantes em Serviço Social que também, em tese, podem ser encontrados na modalidade presencial, bem como em outros campos do saber.

Tais achados são preocupantes quando se considera a fragilidade das condições em que está se dando a formação da base estruturadora dos fundamentos teóricos e metodológicos do Serviço Social para o exercício profissional dos futuros assistentes sociais.

\section{Implicações para a formação profissional dos estudantes em curso de graduação a distância em Serviço Social}

A pesquisa realizada permitiu desvendar, pela ótica das tutoras presenciais, algumas características 
pertinentes à modalidade de ensino. Esse universo que compõe essa nova modalidade aponta implicações para a formação profissional dos estudantes que serão apresentadas a seguir.

\section{Quanto à qualidade técnica no uso da tecnologia da informação e comunicação}

As tutoras presenciais citaram como inadmissível a limitação imposta por qualidade técnica insuficiente no uso da tecnologia da informação e comunicação interferindo na qualidade da interação e interatividade. Atribuem tais ocorrências tanto à burocracia como às condições técnicas precárias no uso da tecnologia.

Considerando a importância e ênfase dadas às tecnologias da informação e comunicação nessa modalidade, as tutoras citaram como preocupantes as falhas a que ficam sujeitas as transmissões das videoaulas, da internet, de cortes nas aulas que comprometem o processo educativo e tecnológico:

[...] eu acho que a questão da transmissão, ela deveria ser melhor. A gente tem falhas na transmissão, a gente tem cortes nas aulas, a gente tem, às vezes, dificuldades com a internet e eu acho que são falhas que não poderiam acontecer porque isto que viabiliza o trabalho naquele dia. (Tutora presencial 3).

Registraram, também, que a interação e interatividade acontecem de forma inadequada, seja com os tutores ou com os alunos, com demora nos retornos, o que impossibilita a manutenção de um fluxo ideal para as discussões, debates, orientações, esclarecimentos de dúvidas. A condição de ensino a distância, ou seja, que se propõe a ser mediado pela tecnologia da informação e comunicação, na visão da tutora, deveria estar isenta de ruídos na interação e interatividade.

\section{Quanto ao número reduzido de debates, discussões, aulas e conteúdos}

Do ponto de vista pedagógico, as tutoras reconheceram que essa modalidade de ensino, por ser muito nova, possui muitas fragilidades e citaram o número de aulas por disciplinas e a inflexibilidade da teleaula, que não permite nenhuma proposta de adequação à realidade dos alunos, como fatores limitadores à aprendizagem:
[...] eu acredito que a limitação é o número de aulas, são poucas aulas da disciplina. E aí eu vejo o seguinte, não tem como a gente estender com o aluno uma discussão, não tem como a gente propiciar um debate, nem uma mediação maior porque são poucas aulas por semestre. Cada disciplina tem três a quatro aulas, então, se roda uma disciplina, inicia outra e as aulas são corridas, não se volta ao tema anterior. Então esta é a limitação, se o aluno teve um tema anterior, numa matéria que estava sendo discutida na aula anterior, na aula seguinte é o seguimento da disciplina, mas o conteúdo é diferenciado, não tem como, por exemplo, a gente retomar. Porque se a gente retoma o aluno perde a aula. (Tutora presencial 2).

\section{Quanto à precariedade da avaliação}

O processo avaliativo em cursos a distância tem sido objeto de questionamentos, com alguns autores argumentando a existência de propostas inexequíveis para a avaliação dos estudantes. Para Silva e Santos (2006), em educação a distância deve se evitar a "retórica sedutora" de ideias avaliativas, que não se sustentam na prática. Segundo os autores, o que se busca na educação on-line é transformar o processo de avaliação do modelo quantitativo para o qualitativo, deixando esta de ser somativa para se transformar em formativa, ampliando-se a concepção da prática avaliativa em educação.

Preti (2008), ao tratar da avaliação em educação a distância, relaciona-a diretamente ao sistema de acompanhamento do estudante, do qual fazem parte professores e tutores que deverão realizar a avaliação processual dentro de uma rotina de observação, descrição e análise contínua. Para Preti (2008), o modelo de avaliação deve ser construído e discutido pela equipe pedagógica do curso com a elaboração de estratégias que envolvam diálogo entre os especialistas acadêmicos na proposta destes critérios de avaliação dos pares, nas diversas produções e na autoavaliação. Para o autor, conhecer o projeto político-pedagógico, os objetivos do curso e o perfil da formação dos estudantes é uma condição importante para compor o processo avaliativo.

Uma das tutoras entrevistadas registra sua preocupação quanto à atribuição da avaliação, imputada ao tutor eletrônico, na qual os tutores presenciais não participam efetivamente, pois: 
[...] se aplicasse, por exemplo, o trabalho individual em sala, para produção na hora, seria mais possível ainda eu perceber [a apreensão da aprendizagem]. Agora, eu acho que talvez nem os tutores eletrônicos que corrigem os trabalhos eles dão conta muito de perceber, não porque os trabalhos hoje, quase que na sua maioria, é cópia [sic], 'ctrl+C', 'ctrl $+\mathrm{V}$ '. E nas provas eu acho também que as próprias perguntas dos professores, às vezes, não dão margem para eles apreenderem esta questão crítica, assim, do discurso dos alunos. (Tutora presencial 1).

\section{Quanto à formação em Serviço Social}

Ao percorrer o desenrolar de um curso de graduação em Serviço Social na modalidade a distância, procurou-se conhecer a formação em relação ao projeto ético-político profissional, às Diretrizes Curriculares Nacionais, ao projeto pedagógico e à supervisão direta de estágios em Serviço Social.

A pesquisa realizada fez um percurso quanto à compreensão das tutoras presenciais sobre alguns normativos que dão direção pedagógica e política à formação. Quanto às Diretrizes Nacionais Curriculares, as sete tutoras que responderam ao questionário declararam conhecê-las e concordaram que a opção teórico-metodológica definida pelo projeto político-pedagógico do curso é coerente com as diretrizes nacionais para os cursos de Serviço Social. Uma das tutoras discordou dessa adequação, bem como da adequação do ementário e da bibliografia, dos conteúdos das disciplinas e práticas pedagógicas aos objetivos do curso e ao perfil profissional da formação. Afirmaram, também, não desconhecer a atuação e produção teórica da Associação Brasileira de Ensino e Pesquisa e Serviço Social (ABEPSS) enquanto entidade ligada à formação. Nas entrevistas realizadas, uma tutora relacionou o conhecimento das diretrizes como um dos que fundamentam uma "boa formação". Para a entrevistada, o tutor

[...] tem que ter muita clareza das diretrizes do curso de Serviço Social. E de tudo que fundamenta uma boa formação, o que está relacionado, seja aos fundamentos teóricos, seja aos aspectos ético-políticos do curso. (Tutora presencial 1).

Conforme registrado anteriormente, as tutoras presenciais em sua grande maioria são recém-egressas de cursos de Serviço Social na modalidade presencial. Portanto, esse é o referencial muitas vezes utilizado em suas avaliações sobre o curso de modalidade a distância. Quando questionadas, dentro de sua visão, sobre a coerência dos conteúdos com as diretrizes, uma das tutoras declarou:

[...] acredito que a instituição tem oferecido subsídio para que o aluno aprenda porque as disciplinas oferecidas não são diferenciadas do curso presencial. Então, mesmo que seja em número reduzido, a instituição tem esta preocupação. (Tutora presencial 2).

$\mathrm{Na}$ ótica das tutoras entrevistadas, o curso de Serviço Social a distância proporciona condições para o desenvolvimento da aprendizagem, seja pelo conteúdo disponibilizado via material didático, que segundo elas é coerente com as diretrizes nacionais curriculares, seja pela tecnologia adotada pela instituição. No entanto, na concepção da tutora abaixo, o conteúdo que o curso oferece é reduzido e demanda outras buscas por parte do aluno para ampliação do conhecimento, o que não difere de um curso presencial:

[...] é um modelo de ensino que se o aluno não tiver vontade de buscar para além daquilo que é oferecido, é, é pouco. Eu costumo dizer para os alunos que eles têm condição grande de fazer um curso rasteiro, mas eu acho que isto também é possibilidade, é oferecida no presencial. Mas ele tem chance de fazer um bom curso, se ele assim quiser. Se ele buscar, se ele realmente fizer os trabalhos, se ele buscar coisas para além daquilo que é oferecido. (Tutora presencial 3).

\section{Quanto às inadequações do estágio supervisionado}

A política de estágio - fortalecimento das ações de formação/capacitação dos supervisores, articulação de fóruns de estágio, avaliação permanente, seminários integrados com outras disciplinas, atividades de preparação para inserção do estudante no campo entre outras - não está implementada nos polos. Pelos dados gerados pelas tutoras participantes da pesquisa, há registros de que campos de estágio locais não possuem capacidade de absorver os estudantes. Como alguns polos estão localizados em pequenos municípios, com poucas instituições detentoras de setor ou departamentos 
de Serviço Social, há uma desproporcionalidade entre o número de estudantes que demandam o estágio e a capacidade de absorção destes. Além dessa condição, as tutoras citam a resistência de profissionais assistentes sociais em receber os estudantes da educação a distância. As tutoras expressaram a situação como

[...] um impasse muito grande porque a categoria não quer supervisionar estágio do ensino a distância. É uma realidade que a gente tem hoje. Os alunos, a maioria, muitos estão procurando em município fora, por exemplo, tem muita gente que mora em 'Felicidade' e faz estágio em 'Alegria', 'Paz', porque não tem profissional disposto a supervisionar. A orientação acadêmica a universidade ainda está adaptando, a gente procura dentro do tempo de plantão orientar o estágio, mas a universidade ainda está orientando a gente em relação ao estágio supervisionado. Não tem supervisor acadêmico. (Tutora presencial 4).

As tutoras entrevistadas atribuíram ao estágio a principal ação em que se materializam as discussões sobre a prática. $\mathrm{O}$ tratamento dado à prática profissional pelo currículo ou o "ensino da prática" não é assumido como centralidade e transversalidade às demais disciplinas. $\mathrm{O}$ que converge com Guerra (2006, p. 167), segundo o qual "este ensino se operacionaliza prioritária e, restritivamente, por algumas disciplinas. Aqui, novamente, aparece a clara distinção positivista entre disciplinas teóricas e práticas, mantendo uma relação de subalternidade de umas sobre as outras".

Algumas situações de inadequação já identificadas no ensino presencial repetem-se na educação a distância. A utilização do estágio como mão de obra barata, a inexistência de acompanhamento didático-pedagógico, a falta de acompanhamento sistemático para articulação da teoria e prática, entre outros, também se instalam nessa modalidade de ensino. Ramos (2007) argumenta que o fato dos estagiários atuarem realizando atividades desvinculadas do Serviço Social traz o risco de reconhecerem de forma confusa e desconexa as competências e atribuições profissionais responsáveis pela legitimidade da profissão. Os depoimentos das tutoras apontam para essa direção:

[...] infelizmente, é algo que eu percebo, não só aqui, que os alunos trazem para mim, da prática de estágio, é algo que eu percebo no meu dia a dia como assistente social, é algo que eu também já trago assim, da minha formação acadêmica. A nossa profissão, eu acho que ela cai numa 'fazeção', sabe, ela cai numa prática mecanizada, muito fácil. Então, os alunos quando eles vão pro campo eles percebem isto e trazem isto pra gente sim. É, e aí tem aluno que fala que entrou pro estágio e estão achando que ele é motorista porque ele sabe dirigir. Tem aluno que entra e fala que eles não colocam, não possibilitam pra esse aluno nenhum momento de discussão institucional, de discussão da sua prática ali, colocam-no para fazer alguma prática meio que burocrática, mecanizada. Infelizmente, isto ainda é muito comum aqui. Desde a minha época e, hoje, aqui, no ensino a distância, não tem muita diferença não. (Tutora presencial 1).

\section{Quanto à inexistência de atividades de pesquisa e extensão}

A expectativa de que a educação a distância fosse capaz de promover a qualificação de um contingente de estudantes para a transformação das realidades locais fica comprometida, caso as universidades que oferecem esta modalidade de ensino não se empenhem em desenvolver programas de pesquisa e extensão, cumprindo, assim, a função social da universidade. No caso do Serviço Social sob análise, essa função está explicitada no próprio projeto político-pedagógico do curso, porém não observada na sua implementação.

Para algumas tutoras, o que existe são atividades complementares, pontuais, previstas no projeto pedagógico, realizadas por algumas turmas. Para uma das tutoras, a indissociabilidade entre ensino, pesquisa e extensão não é preocupação da instituição, pois

[...] a vocação dos polos não é uma vocação educacional. Ela é uma vocação de prestação de serviços. Então, o polo não se preocupa e não se propõe a este tipo de atividade não. Isto é uma realidade que eu acho que é uma realidade de ensino de mercadoria, que a gente tem em outros lugares também, certamente. Mas enquanto a vocação não for educacional essas coisas elas não vingam e elas não aparecem e a realidade é essa. O dono do polo, dos polos, ele é um empresário, aquilo ali é a sua empresa que presta um serviço educacional. (Tutora presencial 3). 
Entre essas atividades complementares obrigatórias, tais como programas de iniciação científica, projetos de pesquisa e extensão, uma das tutoras presenciais conclui sobre a inexistência da indissociabilidade do ensino, pesquisa e extensão:

[...] não tem pesquisa e extensão, não tem. Tem o ensino, o que tem aí fora são as atividades complementares que eles têm de fazer, que tem na presencial também, participar de seminários, de cursos, enfim, umas horas extras. Mas extensão e incentivo à pesquisa isso não existe não, não tem. (Tutora presencial 2).

\section{Quanto à ausência de participação estudantil em movimentos coletivos}

As entrevistadas enfatizaram que tudo no ensino a distância é muito corrido, inclusive o tempo que os alunos dispõem, daí a dificuldade de participação na organização estudantil, conforme declara uma das tutoras:

[...] já peguei o nome de cada aluno em sala que gostaria de fazer parte do diretório, de construir um diretório acadêmico. E aí a gente repassa pros alunos, sabe, não sai. Eu acho que falta esta questão que eu falei aqui, desse pertencimento acadêmico. E eu acho que faz muita falta um diretório acadêmico porque, às vezes, eles são cheios de questões que eles não estão concordando com a dinâmica institucional aqui do polo. Que às vezes uma turma, um ou outro aluno de uma turma só, não é suficiente para eles conseguirem uma representação. (Tutora presencial 1).

Conforme registrado acima, a tutora fala do "não pertencimento acadêmico" que pode estar ligado ao conceito de turma conhecido no modelo tradicional da educação e que no ensino a distância, ou se perde, ou se modifica. Braga (2009, p. 188) registra que a inexistência da turma como um sujeito coletivo na EAD configura "uma questão de difícil equacionamento", pois:

É um sério limite, uma vez que, dos processos de produção de conhecimento e de socialização entre os sujeitos de uma turma, para além das relações com os docentes, resultam saberes e vivências de grande relevância para a formação da cidadania e para a construção de trajetórias de seus sujeitos.

\section{Considerações finais}

É importante frisar que a educação, como a sociedade em geral, está imersa neste redemoinho de inovações. A educação a distância, em especial, vem se valendo, sobremaneira, das tecnologias da informação e comunicação como propulsoras das possibilidades de ensinar e aprender sem limitação de lugar, tempo e ritmo entre professor e alunos (LHAMAS, 1990; RUMBLE, 2003; MORAN, 2009).

Lévy (1999) complementa que as tecnologias de informação e comunicação estão promovendo uma profunda mutação da relação com o saber. A educação, ao aproximar-se do ciberespaço, este entendido como o novo meio de comunicação que surge da interconexão mundial dos computadores e do universo das informações que transitam na rede, passa a fazer parte do que chamou de cibercultura. Está compreendida como o conjunto de técnicas materiais e intelectuais, de práticas, de atitudes, de modos de pensamento e de valores que se desenvolvem e se modificam com o crescimento do ciberespaço. Tais transformações impactarão o processo educacional, mas não carregam consigo a possibilidade de salvação ou perdição. Demo (2008) também já alertou que as TIC's não podem ser pensadas como uma panaceia encontrada para a educação ou para a solução dos problemas da humanidade, mas das quais se pode esperar uma contribuição importante nos processos de formação, da aprendizagem e da produção do conhecimento.

Nesta pesquisa, buscou-se apreender como está se configurando a formação de futuros assistentes sociais a partir de cursos já instalados na perspectiva dos tutores presenciais.

Dentre vários fatores analisados e por meio da visão das tutoras presenciais, observa-se que o ensino a distância configura uma situação dada, legal e institucionalizada na política educacional brasileira. Portanto, no universo da categoria profissional dos assistentes sociais, já transitam profissionais advindos do ensino presencial e a distância, do ensino público ou privado.

Se a profissão já vinha lutando pelo seu aprimoramento constante, pela preservação de condições éticas e técnicas, pela sua legitimidade social e por uma educação de qualidade, certamente ne- 
cessitará redobrar suas lutas em direção aos desafios colocados em tempos neoliberais, de retorno a posições neoconservadoras e assistencialistas.

A educação a distância, portanto, vem provocando mudanças nas relações de ensino e aprendizagem, no perfil de discentes e docentes, e se apresentando como uma nova modalidade educacional capaz de ampliar o acesso à educação, à formação continuada. Por estar se consolidando em tempos bem recentes, carece de ser mais bem conhecida, analisada e avaliada, sempre de forma crítica, face as suas implicações no processo de construção do conhecimento e da formação profissional. E, principalmente, remete a uma reflexão de extrema importância e urgência: a permanente discussão sobre a qualidade da educação e da formação profissional, seja qual for a modalidade adotada.

É importante ressaltar que o ensino presencial também sofre de várias limitações na realidade educacional brasileira. No entanto, na atualidade, a educação a distância aparece em destaque nas discussões sobre o sistema educacional brasileiro. Em primeiro lugar, por despertar curiosidades, mudanças no paradigma educacional e desconhecimento, o que produz análises preconceituosas e resistências à modalidade. Em seguida, por se relacionar, também, com a política governamental das últimas décadas, que priorizou a expansão do ensino superior pela via da iniciativa privada, cuja mercantilização da educação e precarização da formação ofuscam o caráter de política social da educação. Assim, o fenômeno da educação a distância demanda participação popular, fiscalização dos órgãos competentes, pesquisas e avaliações sistemáticas, pois, ao implicar a qualidade da formação de futuros profissionais, repercute na qualidade dos serviços prestados por estes à sociedade.

\section{Referências}

ARRUDA, M. Globalização e ajuste neoliberal: riscos e oportunidades. Tempo e presença, Rio de Janeiro, n. 284, p. 5-9, nov./dez. 1995.

BELLONI, Maria Luiza. Educação a distância. 4. ed. Campinas: Autores Associados, 2006. 115 p.

BRAGA, Rosalina Batista. Educação a distância: desafios sociais, pedagógicos e profissionais para a docência. In: CABRAL, Eloisa Helena de Souza, SOUZA NETO, João
Clemente. Temas do Desenvolvimento: reflexões críticas sobre inovações sociais. São Paulo: Expressão \& Arte Editora, 2009. cap.10. p. 179-189.

BRASIL. Congresso Nacional. Decreto n. 5.622 de 19 de dezembro de 2005. Regulamenta o art. 80 da Lei n. 9.394, de 20 de dezembro de 1996, que estabelece as diretrizes e bases da educação nacional. Diário Oficial da República Federativa do Brasil, Poder Executivo, Brasília, DF, 20 dez. 2005. Disponível em: <http://www.planalto.gov. br/ccivil 03/ Ato2004-2006/2005/Decreto/D5622.htm>. Acesso em: $1 \overline{3}$ jun. 2012.

BRASIL. Congresso Nacional. Lei n. 9.394 de 20 de dezembro de 1996. Estabelece as diretrizes e bases da educação nacional. Diário Oficial da República Federativa do Brasil, Poder Executivo, Brasília, DF, 23 dez. 1996. Disponível em: <http://www.planalto.gov.br/ccivil_03/ Leis/L9394.htm>. Acesso em: 13 jun. 2012.

CONSELHO FEDERAL DE SERVIÇO SOCIAL (Org.) Assistentes Sociais no Brasil: elementos para o estudo do perfil profissional. Brasília: CFESS, 2005.

DEMO, Pedro. TICs e Educação. Blog do autor: 2008. Disponível em: <http://pedrodemo.sites.uol.com.br/textos/ tics.html>. Acesso em: 25 jan. 2010.

FREIRE, Paulo. Pedagogia do Oprimido. 32. ed. Rio de Janeiro: Editora Paz e Terra, 2002. 184 p.

GUERRA, Yolanda. Análise dos Dados da Pesquisa sobre o Estado de Arte da Implementação das Novas Diretrizes Curriculares. Texto produzido para a Oficina Descentralizada da ABEPSS " 10 anos de diretrizes curriculares - um balanço necessário", realizada no período de 14 a 16 de agosto de 2006, na Universidade Federal de Juiz de Fora (UFJF-MG) e apresentado na Oficina Nacional Descentralizada ABEPSS Regional Leste em 2006.

IAMAMOTO, Marilda Villela. O Serviço Social na contemporaneidade: trabalho e formação profissional. 4. ed. São Paulo: Cortez Editora, 2001. 326 p.

LÉVY, Pierre. Cibercultura. Tradução Carlos Irineu da Costa. São Paulo: Editora 34, 1999. 264 p.

LHAMAS, José Garcia et al. Analisis y Valoracion Del Modelo Español de Educacion Superior a distancia - Memoria Del Proyecto de Investigacion. Madrid, fev. 1990. 348 p. Disponível em: <http://www.doredin.mec.es/ documentos/008199300079.pdf $>$. Acesso em: 13 jun. 2012.

LITWIN, Edith. Das tradições à virtualidade. In: (Org.) Educação a Distância: temas para o debate de uma nova agenda educativa. Tradução Fátima Murad. Consultoria, supervisão e revisão técnica de Juliane Corrêa. Porto Alegre: Editora Artmed. 2001. Cap.1. p. 13-22.

MAGGIO, Mariana. O tutor na educação a distância. In: LITWIN, Edith (Org.) Educação a Distância: temas para 
o debate de uma nova agenda educativa. Tradução Fátima Murad. Consultoria, supervisão e revisão técnica de Juliane Corrêa. Porto Alegre: Editora Artmed, 2001. cap.6. p. 93110.

MORAN, José Manuel. Modelos e Avaliação do Ensino Superior a Distância no Brasil. Revista ETD - Educação Temática Digital, Campinas: v. 10, n.2, p. 54-70, jun. 2009. Disponível em: <http://www.fae.unicamp.br/etd/>. Acesso em: 13 jun. 2012.

Tendências da educação on line no Brasil. In: RICARDO, Eleonora Jorge (Org.). Educação corporativa e educação a distância. Rio de Janeiro: Editora Qualitymark, 2005. Disponível em: <http://www.eca.usp.br/prof/moran/ tendencias.htm>. Acesso em: 13 jun. 2012.

MORIN, Edgar; CIURANA, Emilio-Roger; MOTTA, Raúl Domingo. Educar na Era Planetária: o pensamento complexo como método de aprendizagem pelo erro e incerteza humana. 2. ed. São Paulo: Cortez Editora, 2007. 111 p.

PRETI, Oreste. Avaliação da Aprendizagem em Cursos a Distância: delegando responsabilidades aos tutores? Núcleo de Educação Aberta e a Distância (NEAD) - Instituto de Educação.Universidade Federal de Mato Grosso (UFMT) 2008. Disponível em <http://200.169.53.89/download/ CD\%20congressos/2008/V\%20ESUD/trabs/t38546.pdf>. Acesso em: 25 jan. 2010.

RAMOS, Sâmya Rodrigues. A prática na formação profissional em Serviço Social: tendências e dificuldades. Temporalis, São Luis, ano VII, n. 14, p. 149-174, jul/ dez. 2007.

RUMBLE, Greville. A gestão dos sistemas de ensino a distância. Brasília: Editora Universidade de Brasília/ Unesco, 2003. 120 p.

SILVA, Marco; SANTOS, Edméa. Avaliação da aprendizagem em educação on line. São Paulo. Ed. Loyola. 2006. 537p.

TRÓPIA, Patrícia Vieira. O Ensino superior em disputa: apoio e alianças de classe à política para o ensino superior no governo Lula. In: REUNIÕES ANUAIS DA ANPED, 31., 2008, Campinas. GT 11: Política da Educação Superior. Associação Nacional de Pós Graduação e Pesquisa em Educação. Campinas: ANPED, 2008. Disponível em: $<$ http://www.anped.org.br/reunioes/31ra/1trabalho/GT113987--Int.pdf>. Acesso em: 13 jun. 2012.

Data de Submissão: outubro de 2012

Data de Aprovação: maio de 2013 